\title{
Processing and learning from multiple sources: A comparative case study of students with dyslexia working in a multiple source multimedia context
}

\author{
Anette Andresen ${ }^{a}$, Øistein Anmarkrud ${ }^{a}$, Ladislao Salmerón ${ }^{b}$, and Ivar Bråten ${ }^{a}$ \\ ${ }^{a}$ University of Oslo, Norway \\ bUniversity of Valencia, Spain
}

Article received 22 January / Revised 2 May / Accepted 2 June / available online 16 July

\begin{abstract}
This study investigated how four 10th-grade students with dyslexia processed and integrated information across web pages and representations when learning in a multiple source multimedia context. Eye movement data showed that participants' processing of the materials varied with respect to their initial exploration of the web pages, their overall processing time, and the linearity of their processing patterns, with post-learning interviews indicating the deliberate, strategic considerations underlying each participant's processing pattern. Eye movement data in terms of fixation duration and percentage of regressions also corroborated the findings of formal, diagnostic assessments. Finally, it was found that participants differed with respect to how much factual information they learned from working with the materials and how well they were able to integrate information across the web pages and representations, with results suggesting particular problems with learning factual information and, at the same time, constructing a coherent mental representation of the issue, as well as with drawing on textual information in the integration process. This study brings together two research areas that essentially have been kept apart in theory and research, that is, dyslexia and multimedia learning, and it provides unique information about the role of individual differences in multiple source multimedia contexts.
\end{abstract}

Keywords: Multiple source use; dyslexia; Eye-tracking; Strategic processing; Multimedia learning

Corresponding author: Øistein Anmarkrud, University of Oslo, Department of Special Needs Education. P.O. Box 1140 Blindern, N-0318 Oslo, Norway, oistein.anmarkrud@isp.uio.no DOI: $10.14786 /$ flr.v7i3.451 


\section{Introduction}

Due to technological developments, human learning is becoming increasingly multi-representational (Ainsworth, 2018). Accordingly, learning in school has become much more than reading and understanding textbooks. One reading context where students encounter multimedia information on a regular basis is the Internet, making it possible for students to benefit from texts, pictures, animations, films, and interactive graphs. Hence, the Internet has become an invaluable learning tool for students, providing them with a vast amount of multimedia information that they can use for academic purposes (e.g., Kammerer, Meier, \& Stahl, 2016; Kingsley \& Tancock, 2013; Mason, Junyent, \& Tornatora, 2014; van Strien, Brand-Gruwel, \& Boshuizen, 2014).

However, although the abundant information available just a finger swipe or mouse click away has brought new affordances for learning, it also comes with some caveats. Successful learning from the Internet requires learners to integrate task-relevant and reliable information across different representations (e.g., pictures, videos, and texts), web pages, and perspectives, as well as with their own prior knowledge (e.g., Bråten, Braasch, \& Salmerón, in press; Cho, Woodward, \& Li, 2017; DeSchryver, 2015; Rouet \& Britt, 2014). Presumably, learning from multimedia materials, that is, the construction of a coherent mental representation based on information from different types of media, requires considerable working memory resources (e.g., Irrazabal, Saux, \& Burin, 2016; Schüler, Scheiter, \& van Genuchten, 2011; Sweller, Ayres, \& Kalyuga, 2011).

In explaining the relationship between multimedia learning and working memory, Mayer's (2003, 2014a) influential cognitive theory of multimedia learning draws on limited-capacity (Baddeley, 1995, 2000; Just \& Carpenter, 1992) and dual-channel theories (Baddeley, 1995; Clark \& Paivio, 1991; Paivio, 1971, 1986). The limited-capacity theory assumes that human working memory is limited in capacity and, thus, can process only a certain amount of information at a time. If processing demands exceed this limited capacity, the likely result is cognitive overload, which reduces learning. The dual-channel theory assumes that visual and auditory information is processed in separate channels in working memory and that these channels operate independently from each other, each with its own capacity. Hence, when these two channels are combined, such as when a multimedia learning context involves both a text (visual channel) and a narration (auditive channel), the learner will be able to process more information simultaneously than when the learning context involves a combination of text and pictures, since both text and pictures have to be processed in the visual channel. However, current web pages, often containing text, pictures, animations with narration, audio files, and so forth, have the potential to overload both the visual and the auditive channel in working memory (Knoop-van Campen, Segers, \& Verhoven, 2018; Schüler et al., 2011).

When students use the Internet for educational purposes, they often visit several web pages that may present overlapping, complementary, and conflicting information (Cho, Afflerbach, \& Han, 2018; Cho et al., 2017; Salmerón, Strømsø, Kammerer, Stadtler, \& van den Broek, 2018), with successful learning demanding integration across different representations (e.g., text, video, and picture) and web pages. Although this can represent a great challenge for students regardless of their reading skills, poor readers may be particularly vulnerable in such learning contexts. Still, surprisingly little is known about how students with dyslexia handle such multi-representational information (Anmarkrud, Brante, \& Andresen, 2018; Knoop-van Campen et al., 2018; McCarthy \& Swierenga, 2010), compared to the knowledge that exists about typically developing readers' multimedia learning (Mayer, 2014c). This study is frontline because it uniquely contributes to both multimedia learning and dyslexia, integrating and broadening the research agenda in both areas and providing new insights into what it means to be a struggling reader in the 21 st century. One pertinent question is how the combined processing demands imposed by the multimedia context along with the processing demands of reading could affect comprehension and learning from multimodal materials for readers with dyslexia. Hence, the present study aimed to provide a detailed description of some of the potential challenges that students with dyslexia may experience when trying to integrate information across representations (i.e., texts, pictures, and videos) and web pages by means of a comparative case study of four adolescents with dyslexia working on a socio-scientific issue in a digital environment. As such, this study draws on theoretical and empirical work on 
information processing in multimedia learning and attempts to extend that work to the challenges faced by readers with dyslexia in a multimedia learning context.

\subsection{Developmental Dyslexia}

Dyslexia is a specific learning disability characterized by difficulties with accurate and/or fluent word recognition, poor decoding skills, and spelling difficulties (Lyon, Shaywitz, \& Shaywitz, 2003). The associated reading and writing difficulties are typically a result of a deficit in the phonological component of language (e.g., Harm \& Seidenberg, 1999; Ramus et al., 2003). Dyslexia is found to affect between 3 and 7\% of the population (Hulme \& Snowling, 2009) and is assumed to be of neurobiological origin (e.g., Shaywitz \& Shaywitz, 2008). Although there is no "cure" for dyslexia, several studies have shown that many children with dyslexia can develop reading skills comparable to typically developing readers when provided necessary support and high-quality remedial reading instruction (e.g., Hulme \& Snowling, 2009; Torgersen, 2001; Torgersen et al., 2001). However, there are substantial differences in reading skills among students with dyslexia, and those towards the severe end of the spectrum may struggle with reading long into adolescence and adulthood.

Further, individuals with dyslexia have often been found to have working memory problems (e.g., Avons \& Hanna, 1995; Barbosa, Miranda, Santos, \& Bueno, 2009; Melby-Lervåg, Lyster, \& Hulme, 2012), not only with the processing of information in a phonological code but also with central executive domains and the processing of visual information (e.g., Fischbach, Könen, Rietz, \& Hasselhorn, 2014; Menghini, Finzi, Carlesimo, \& Vicari, 2011; Smith-Spark \& Fisk, 2007). It is assumed that the working memory deficits often seen among individuals with dyslexia may contribute to difficulties constructing a coherent representation of a text during reading, independent of their difficulties with phonological coding (e.g., Berninger, Raskind, Richards, Abbot, \& Stock, 2008; Borella, Carretti, \& Pelegrina, 2010; Follmer, 2018; Smith-Spark \& Fisk, 2007). However, several studies have found substantial within-group-heterogeneity in working memory capacity among students with dyslexia (e.g., Gathercole, Alloway, Willis, \& Adams, 2006; Jeffries \& Everatt, 2004; Smith-Spark \& Fisk, 2007).

\subsection{Learning from Multiple Representations in a Digital Context}

Up to the early 2000 s, research examining reading comprehension and text-based learning typically involved a reader encountering a single text, usually on paper. With the development of new and user-friendly information technologies, such as the Internet, the conception of what constitutes a typical reading situation has changed considerably (Bråten et al., in press; Cho et al., 2018; Fox \& Alexander, 2017; Leu, Kiili, \& Forzani, 2016; Salmerón et al., in press). Whereas conventional printed textbooks typically include text and various forms of illustrations and as such can be labelled multimedia materials, the digital learning contexts of today provides a variety of representations (e.g., animations, videos, audio files, simulations) in addition to text and pictures. Research on multimedia learning originally focused on learning from a combination of text and pictures in an offline context (Butcher, 2014; Mayer, 2014b). However, given the technological developments in recent decades, multimedia learning has come to refer to the combination of any type of words and visual displays, regardless of whether the learning occurs in a non-digital or digital context.

Several cognitive models have been developed to explain multimedia learning, with Mayer's (2001, 2014b) cognitive theory of multimedia learning being the most influential. The basic assumption of this model is that multimedia learning rests on a cognitive system with multiple memory stores, with a working memory system of limited capacity considered an essential processing component. Also, the model posits that good multimedia learning requires the integration of information from various representations and that comprehension and learning can be hampered by the constraints of the human cognitive system, particularly working memory (e.g., Chan \& Unsworth, 2011; Mayer \& Moreno, 2010; Schüler et al., 2011). 
A significant body of research indicates that using multiple representations in academic learning contexts may be beneficial (e.g., Butcher, 2014; Cuevas, Fiore, \& Oser, 2002; Rieber, Tzeng, \& Tribble, 2004). However, poorly designed multimedia learning environments can increase working memory load, leading to reduced learning. One example is when an additional representation (e.g., a picture added to a text) does not contain new information. In such a case, learners will have to waste additional processing capacity on the redundant information from the added representation without gaining any new knowledge. This is often referred to as the redundancy effect and has been found to interfere with learning (e.g., Gerjets, Scheiter, Opfermann, Hesse, \& Eysink, 2009; Pociask \& Morrison, 2008; Torcasio \& Sweller, 2010). Another example is that presenting information by means of more than two representations in and of itself can increase processing demands, particularly when the representations are physically or temporally disparate (Ayres \& Sweller, 2014). In such a situation, learners would have to split their attention between the different representations and fill the "gaps" between representations by drawing inferences before integrating information across the representations. This is referred to as the split-attention effect, and it can potentially reduce learning, especially among learners with reduced working memory capacity (Fenesi, Kramer, \& Kim, 2016).

In brief, the use of multimedia has the potential to increase learning when multimedia environments are designed according to the limitations of the human information processing system. However, ill-structured multimedia environments have the potential to reduce learning, compared to single-media environments, due to increased load on working memory.

\subsection{Dyslexia and Learning from Multiple Representations}

Thus far, few studies have been conducted on multimedia learning among students with dyslexia. In a recent study, Knoop-van Campen et al. (2018) examined how multiple representations affected learning and study time among 11-year-old students with dyslexia compared to typically developing readers. The participants worked with three user-paced multimedia lessons on the topics of balance in nature, motion, and global warming, and participants were divided into three conditions: 1) pictures + text, 2) pictures + audio, and 3) pictures + text + audio. The participants studied every lesson once, and learning was assessed at two time points; at one immediate posttest and a delayed posttest one week later. The results showed that in the picture + text condition, the dyslexic participants spent statistically significantly longer time working with the materials than did the non-dyslexic participants. There were no statistically significant differences in study time between the two groups in the two other conditions, and there was no statistically significant correlation between study time and learning in any of the conditions. Further, there were no main effects of condition, group, or working memory capacity on learning measured at the immediate and delayed posttests, although participants with dyslexia had statistically significantly lower scores on the working memory measure compared to the participants without dyslexia.

A study by MacCullagh, Bosanquet, and Badcocks (2017) highlights the challenges students with dyslexia may have integrating information across representations. Interviews were conducted with 13 university students with dyslexia to investigate how they used an available multimedia tool consisting of videorecorded lectures in combination with other representations such as animations and text boxes to compensate for their reading difficulties. Several participants reported that recorded lectures that they viewed with this tool were challenging to follow when all the different representations were combined. The participants reported that they often had to go through the online lectures several times to be able to benefit from them (e.g., just listen to the lecturer the first time, pay attention to the animation and text boxes the second time, and take notes the third time).

In two studies, Alty and colleagues (Alty, Al-Sharrah, \& Beacham, 2006; Beacham \& Alty, 2006) examined the effects that different combinations of representations, such as textual and visual materials (e.g., diagrams) as well as audio files (voice over), had on the learning of statistics among students with dyslexia. In the first study, Alty et al. (2006) compared students with and without dyslexia across three conditions: one group received the learning materials as text only, one group received the materials as diagrams + voice over, 


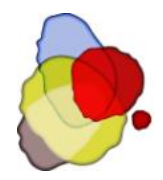

and one group received the materials as text + diagrams. The results showed, contrary to expectations, that the students with dyslexia in the text-only condition significantly outperformed the students with dyslexia in the two other conditions with regard to learning, whereas the students without dyslexia in the diagrams + voiceover condition performed better than the students without dyslexia in the two other conditions. Given the somewhat surprising finding concerning the participants with dyslexia, Beacham and Alty (2006) conducted the same experiment with a larger sample of students with dyslexia, this time without a non-dyslexic control group. The results in this second study corroborated the findings from the original study; again, the participants in the text-only condition outperformed the students in the two other conditions regarding learning, despite reporting that this was the least preferred version of the learning materials.

\subsection{Integration as Strategic Activity}

According to Cho and Afflerbach (2017), integration of information across representations and web pages requires strategic activity in the service of creating meaning. More generally, comprehension strategies may be defined as intentional attempts to control and modify meaning construction during learning (cf., Afflerbach, Pearson, \& Paris, 2008). If the semantic overlap between representations or sources is high, integration may rely on automatic processing (Myers \& O'Brien, 1998). If not, integration will have to rely on deliberate, strategic activity (Kurby, Britt, \& Magliano, 2005), with the execution and monitoring of strategies drawing on working memory resources. Presumably, multimedia learning that requires strategic processing will be particularly challenging for learners with dyslexia, who also must spend considerable working memory resources on more basic reading processes. Of note is also that multimedia materials, such as online sources, are not necessarily designed according to multimedia principles (e.g., Mayer, 2014b), that is, to reduce the load on working memory. Several studies clearly have indicated that strategic behavior, such as coordinating representations and actively searching for meaning in different sources, can facilitate the integration of information into a coherent and rich mental model when working with multimedia materials (e.g., Azevedo \& Cromley, 2004; Greene, Moos, Azevedo, \& Winters, 2008; Moreno \& Mayer, 2000).

\subsection{The Present Study}

Although it has been argued that learning in multimedia contexts, such as the Internet, could be beneficial for struggling readers because text is supplemented with other representations (Castek et al., 2011; Henry et al., 2012), learning in such contexts also may represent particular challenges for struggling readers. This is because a combination of processing demands associated with word reading and processing demands associated with integrating information across web pages and representations may lead to cognitive overload (Chan \& Unsworth, 2011). In this study, we extended previous research by exploring variations in the processing patterns of adolescent readers with dyslexia who worked with conflicting web pages containing multiple representations. Additionally, we set out to explore how these processing patterns were related to cognitive differences among participants and to their performance on post-reading learning and integration tasks. To be able to address these issues in depth, we opted for a comparative case study design (Yin, 2009) combining quantitative and qualitative data. Specifically, following the logic of a comparative case approach (Campbell, 2012; Yin, 2009), we selected four cases that were analysed independently before they were compared and contrasted.

The study of these cases was guided by two research questions. First, to what extent do different processing patterns displayed by students with dyslexia when reading multimodal information represent deliberate, strategic activity? We expected that processing time would be related to the severity of the participants' reading difficulties, with more severe reading difficulties associated with longer processing time due to the time spent on reading the texts on the web pages. Moreover, prior research with typically developing readers in multimedia learning contexts has shown that the order in which representations are processed, and the transitions between representations, can influence learning outcomes (e.g., Mason, Pluchino, \& Tornatora, 2016; Mason, Scheiter, \& Tornatora, 2017). Two different approaches to the integration of textual and pictorial 


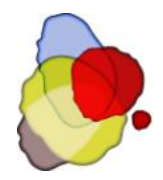

information in multimedia contexts have been described in the literature. The first approach, picture-to-text processing, involves a brief inspection of pictures before processing textual material, with a quick examination of a picture providing a global spatial representation of the topic that, in turn, can scaffold comprehension of the text material. Recent research has found a positive effect of the picture-to-text approach (Eitel, Scheitel, \& Schüler, 2013; Eitel, Scheiter, Schüler, Nyström, \& Holmqvist, 2013; Mason et al., 2017). The second approach, text-to-picture processing, involves processing textual material first, which may help readers focus on the essential elements of a picture subsequently. This approach also has been found to facilitate learning in multimedia contexts (Hegarty \& Just, 1993). Which of these approaches is the most efficient is probably a matter of the complexity of the information conveyed by the different representations, with the representation containing the least complex information preferably processed first (Eitel \& Scheiter, 2015; Mason et al., 2017). Considering that our participants were students with dyslexia, we expected that participants with a deliberate, strategic processing pattern would use the picture-to-text approach to try to compensate for their word reading problems.

Second, how are processing patterns related to individual differences among participants and to their learning from and integration of multimodal information presented on different web pages? Several studies have indicated that students with dyslexia who have developed sufficient word decoding skills through adequate remedial reading instruction may display reading comprehension almost on a par with students without dyslexia (e.g., Bishop \& Snowling, 2004; de Olivera, da Silva, Dias, Sebra, \& Macedo, 2014; Torgersen, 2001; Torgersen et al., 2001). Although there are very few studies examining comprehension of graphics (both static and motion) among individuals with dyslexia, available studies do not indicate that they have particular problems extracting information from pictorial representations (Abtahi, 2012; Roca, Tejero, \& Insa, 2018; Taylor, Duffy, \& Hughes, 2007). Hence, we expected that the participants would be able to gain factual knowledge from all representations and web pages used in this study. However, because integration of information from multiple representations imposes considerable processing demands on working memory, and because students with dyslexia have been found to display working memory deficits, we expected that integrating information across representations and web pages would be a profound challenge for our participants. Further, we expected that the participants would be inclined to draw more on information from pictures and videos than on information conveyed by textual material when trying to construct a coherent mental representation of the learning materials.

This research is based on a sample of 22 tenth-graders with dyslexia who participated in a study investigating differences in multiple source use between students with and without dyslexia (Andresen, Anmarkrud, \& Bråten, 2019). That study indicated that the group of students with dyslexia was heterogeneous with respect to working memory capacity and reading skill. Hence, to examine in depth how differences in these two key competencies might influence the processing of and learning from multiple multimedia sources in a digital environment, we selected participants with dyslexia who varied with respect to working memory capacity and reading skill for this comparative case study.

\section{Method}

\subsection{Participants}

The participants were four Norwegian adolescents, ranging in age from 15 years 9 months to 15 years 11 months. In Norway, if there is concern about a student's reading proficiency, the student will be assessed by an educational-psychological service (EPS). If appropriate, the students will be diagnosed with dyslexia based on test results, classroom observations, and interviews with parents and teachers. Students who receive remedial reading instruction according to The Special Needs Education Act are usually reassessed every other year. Thus, the four participants in this study were diagnosed by experts at the EPS within the last two years. Their diagnoses were based on criteria included in the definition of dyslexia proposed by Lyon et al. (2003). This means that the four participants displayed difficulties in word recognition, phonological processing, and 
spelling (Lyon et al., 2003). Specifically, all participants were assessed with standardized diagnostic test batteries called Logos (Høien, 2014) or STAS (Klinkenberg \& Skaar, 2003), which are frequently used in Norway and other Scandinavian countries to diagnose dyslexia. On these test batteries, all participants with dyslexia scored below the 15th percentile on subtests measuring reading fluency, word identification, phonological processing, and spelling and were simultaneously within the normal range on subtests measuring listening comprehension. None of the participants had comorbid conditions such as attention deficit disorder, language impairment, or more general learning disabilities. All participants had normal or corrected to normal vision. See Table 1 for relevant background information about each of the four participants.

Table 1

Background information about the four participants

\begin{tabular}{lllll}
\hline & Participant 1 & Participant 2 & Participant 3 & Participant 4 \\
\hline Time of dyslexia diagnosis & 4th grade & 6th grade & 8th grade & 5th grade \\
$\begin{array}{l}\text { Reading level (percentile) } \\
\text { Phonological reading }\end{array}$ & $1.2^{1}$ & $12.8^{2}$ & $14.7^{2}$ & $14.1^{1}$ \\
Orthographic reading & $0.1^{1}$ & $9.6^{2}$ & $11.1^{2}$ & $10.3^{1}$ \\
$\quad$ Reading fluency & $0.2^{1}$ & $8.2^{2}$ & $10.7^{2}$ & $2.8^{1}$ \\
Working memory capacity & $4(z=-2.08)^{4}$ & $13(z=-1.10)^{4}$ & $32(z=.96)^{4}$ & $16(z=-.77)^{4}$ \\
\hline
\end{tabular}

Note ${ }^{1}$ Measured with Logos (Høien, 2014), ${ }^{2}$ measured with STAS (Klinkenberg \& Skaar, 2003), ${ }^{3}$ measured with a Norwegian adaption of Swanson and Trahan's (1992) Working Memory Span Task, ${ }^{4}$ compared to the mean scores of a sample of 528 Norwegian 10th and 11th graders (Anmarkrud \& Ferguson, 2011).

Participant 1 was diagnosed with dyslexia in 4th grade. The latest EPS assessment showed that this participant still had substantial reading difficulties, with very low scores on subtests measuring phonological word reading (nonword reading; 1.2 percentile), orthographic reading ( 0.1 percentile), and reading fluency ( 0.2 percentile). Based on the thorough reading assessment at the EPS, Participant 1 was by far the weakest reader among the four participants. As seen in Table 1, Participant 1 also displayed a very limited working memory capacity.

Participant 2 was diagnosed with dyslexia in 6th grade. On the latest EPS assessment, Participant 2 scored approximately two grades below the current grade level on subtests measuring phonological reading (nonword reading), orthographic reading, and reading fluency. However, presumably due to very good language comprehension skills, Participant 2 seemed to be able to compensate for the word reading problems and had grade-appropriate reading comprehension scores. Hence, Participant 2 could be characterized as a poor word decoder with relatively good comprehension skills.

Participant 3 was not diagnosed with dyslexia until 8th grade. In the report from the EPS, this participant was described as a very motivated and academically sound student with excellent learning abilities (e.g., a relatively high working memory capacity). Due to these strengths, Participant 3 had been able to conceal and compensate for the word reading problems for many years, and it was not until entering 8th grade, where the reading materials in school became increasingly more complex, that the reading difficulties became very visible. The EPS assessment showed that Participant 3's scores on tests measuring phonological reading (nonword reading), orthographic reading, and reading fluency were equivalent to what is typically found among students two years younger.

Participant 4 was diagnosed with dyslexia in 5th grade. The results on the latest EPS assessment showed that this participant mastered a phonological word reading task (i.e., could read the nonwords correctly) but was very slow on this task compared to typically developing peers. Participant 4 demonstrated substantial difficulties on subtests measuring phonological awareness, orthographic reading, and reading fluency, with scores well below the 15 th percentile on these subtests. 
Table 2

Content of the three web pages

\begin{tabular}{|c|c|c|c|c|}
\hline \multirow{3}{*}{$\begin{array}{l}\text { Web } \\
\text { page } 1\end{array}$} & & \multicolumn{3}{|c|}{ Representation } \\
\hline & & Video & Text & Picture \\
\hline & $\begin{array}{l}\text { Title: Different types } \\
\text { of UV radiation } \\
\text { Lead paragraph: This } \\
\text { web page is about } \\
\text { different types of UV } \\
\text { radiation and the } \\
\text { strength of this } \\
\text { radiation. }\end{array}$ & $\begin{array}{l}\text { A two-minute-long } \\
\text { interview with a physics } \\
\text { professor explaining how } \\
\text { the ultraviolet radiation } \\
\text { (UV) index is used to } \\
\text { measure the strength of UV } \\
\text { radiation. The professor } \\
\text { also explains how seasons, } \\
\text { clouds, thickness of the } \\
\text { ozone layer, water, and } \\
\text { snow affect the strength of } \\
\text { UV radiation. Finally, the } \\
\text { professor explains that UV } \\
\text { radiation in a sunbed is } \\
\text { usually more intense than } \\
\text { in natural sunlight. }\end{array}$ & $\begin{array}{l}\text { An } 83 \text {-word text explaining } \\
\text { that UV radiation is a type } \\
\text { of electromagnetic } \\
\text { radiation coming from the } \\
\text { sun. The text also explains } \\
\text { that UV radiation can be } \\
\text { found in sunbeds. }\end{array}$ & $\begin{array}{l}\text { The picture } \\
\text { describes the three } \\
\text { different types of } \\
\text { UV radiation (UV } \\
\text { A, B, and C) and } \\
\text { that it is UV A that } \\
\text { gives us a tan and } \\
\text { UV B that makes us } \\
\text { sunburned, while } \\
\text { UV C is stopped by } \\
\text { the ozone layer and } \\
\text { does not reach the } \\
\text { ground. }\end{array}$ \\
\hline $\begin{array}{l}\text { Web } \\
\text { page } 2\end{array}$ & $\begin{array}{l}\text { Title: UV radiation } \\
\text { and cancer } \\
\text { Lead paragraph: This } \\
\text { web page is about the } \\
\text { risks related to } \\
\text { sunbathing, different } \\
\text { types of cancer, and } \\
\text { how you can protect } \\
\text { yourself against the } \\
\text { sun. }\end{array}$ & $\begin{array}{l}\text { A one-minute animation } \\
\text { explaining two types of } \\
\text { skin cancer that are related } \\
\text { to sun exposure: basal cell } \\
\text { carcinoma and melanoma. } \\
\text { The risk of getting these } \\
\text { types of cancer are linked } \\
\text { to the strength of UV } \\
\text { radiation and how long the } \\
\text { skin is exposed to UV } \\
\text { radiation }\end{array}$ & $\begin{array}{l}\text { A 92-word text explaining } \\
\text { how UV radiation can } \\
\text { damage our DNA and that } \\
\text { such damage is linked to } \\
\text { the development of skin } \\
\text { cancer. The text refers to } \\
\text { research providing } \\
\text { evidence for the increased } \\
\text { risk of skin cancer related } \\
\text { to the use of sunbeds }\end{array}$ & $\begin{array}{l}\text { The picture } \\
\text { describes } \\
\text { precautions that } \\
\text { should be taken to } \\
\text { reduce the risk of } \\
\text { skin cancer, such as } \\
\text { sunscreen, sun } \\
\text { glasses, avoiding } \\
\text { sunbeds, and } \\
\text { staying in the } \\
\text { shade/out of the } \\
\text { sun. }\end{array}$ \\
\hline $\begin{array}{l}\text { Web } \\
\text { page } 3\end{array}$ & $\begin{array}{l}\text { Title: Do you get } \\
\text { enough sun? } \\
\text { Lead Paragraph: This } \\
\text { web page is about the } \\
\text { sun as an important } \\
\text { source for Vitamin D } \\
\text { and the importance of } \\
\text { Vitamin D for our } \\
\text { health. }\end{array}$ & $\begin{array}{l}\text { A one-minute animation } \\
\text { presenting the results from } \\
\text { a recent longitudinal study } \\
\text { with } 50000 \text { participants } \\
\text { that examined the } \\
\text { beneficial effects of } \\
\text { vitamin D. The study } \\
\text { found that } 5 \text { micrograms of } \\
\text { vitamin D every day } \\
\text { reduced the risk of cancer } \\
\text { with } 33 \% \text {, the risk of } \\
\text { prostate cancer and } \\
\text { colorectal cancer. Vitamin } \\
\text { D hampers abnormal cell } \\
\text { growth that is found in } \\
\text { cancer. }\end{array}$ & $\begin{array}{l}\text { A 90-word text arguing that } \\
\text { the campaigns that tell } \\
\text { people to stay out of the } \\
\text { sun or use sunscreen have } \\
\text { gone too far. The sun is an } \\
\text { important source of vitamin } \\
\mathrm{D} \text {, and the text argues such } \\
\text { campaigns could have } \\
\text { serious consequences. The } \\
\text { text refers to research } \\
\text { saying that cancer patients } \\
\text { have better prognoses if } \\
\text { their disease is discovered } \\
\text { in the summer or fall, when } \\
\text { their vitamin D storages are } \\
\text { full. }\end{array}$ & $\begin{array}{l}\text { The picture } \\
\text { explains that } 30 \\
\text { minutes in the sun } \\
\text { without sunscreen } \\
\text { in the summer, or } \\
30 \text { minutes in a } \\
\text { sunbed during the } \\
\text { winter, would give } \\
\text { the same amount of } \\
\text { vitamin D as a } \\
\text { small bottle of cod } \\
\text { liver oil (a vitamin } \\
\text { D supplement used } \\
\text { in Norway). }\end{array}$ \\
\hline
\end{tabular}

\subsection{Learning Materials}

Participants were given access to a researcher-generated Internet site presented in an offline mode that was titled "Sunbathing and health". The site contained three different web pages about the controversial issue of sun exposure and health. These web pages presented two main perspectives: sun exposure is beneficial, and 
sun exposure is harmful. Each web page contained a title and a lead paragraph explaining the overall content of that page and then presented a video, a short text, and a picture, in that order. The first page contained information about the nature of ultraviolet radiation, different wavelength bands, how ultraviolet radiation is measured, and how different types of ultraviolet radiation affect the skin. The second page presented research arguing that sun exposure is healthy because it increases the production of vitamin $\mathrm{D}$, which can protect against cancer, particularly in inner organs. The third page focused on the harmful effects of sun exposure due to increased risk of skin cancer, particularly basal cell carcinoma and melanoma, and explained that sun exposure cannot be considered a safe source of vitamin D. The main idea units of the different representations (i.e., the texts, the videos, and the pictures) were unique, which made it possible to trace each idea unit in participants' post-reading answers back to a particular representation on a particular web page. Of note is that the learning materials were designed in accordance with design principles for multimedia learning (Mayer, 2014a). Thus, we took the spatial contiguity principle (e.g., Austin, 2009; Johnson \& Mayer, 2012) into consideration by presenting text, videos, and pictures near each other on the web pages, and we omitted redundant information across the different representations in accordance with the redundancy principle (e.g., Mayer, Heiser, \& Lonn, 2001; Moreno \& Mayer, 2002). Table 2 provides an overview of the content of the three web pages.

The texts that were included on the web pages (one on each page) contained 83, 92, and 90 words, and ranged in readability from 37 to 40 (see Table 3). These readability scores were based on Björnsson's (1968) formula, taking word length and sentence length into consideration. This formula yields readability scores ranging from approximately 20 (very easy text) to approximately 60 (very difficult text). Vinje (1982) reported that textbooks used in Norwegian upper-secondary school had a readability score of approximately 42 and that public information texts from the Norwegian government had a readability of 45 .

Table 3

Descriptive information about the text on each of the three web pages

\begin{tabular}{lllllll}
\hline & $\begin{array}{l}\text { No. of } \\
\text { words }\end{array}$ & $\begin{array}{l}\text { No. of } \\
\text { sentences }\end{array}$ & $\begin{array}{l}\text { M words } \\
\text { per sentence }\end{array}$ & $\begin{array}{l}\text { No.of } \\
\text { characters } \\
\text { in text }\end{array}$ & $\begin{array}{l}M \\
\text { characters } \\
\text { per word }\end{array}$ & Readability \\
\hline Text page 1 & 83 & 6 & 13.83 & 436 & 5.25 & 38 \\
Text page 2 & 90 & 7 & 12.86 & 448 & 4.97 & 37 \\
Text page 3 & 92 & 6 & 15.33 & 452 & 4.91 & 40 \\
\hline
\end{tabular}

\subsection{Measures}

\subsubsection{Topic knowledge measure.}

To assess students' knowledge about the topic of sun exposure and health, both before and after working on the learning materials described above, we used a 12-item multiple-choice test. The items referred to concepts and information central to the issue of sun exposure and health that were discussed on the three web pages. Because the same measure was administered both before and after participants worked on the learning materials, learning gain could be calculated by subtracting the number of correct responses out of 12 on the first occasion from the number of correct responses out of 12 on the second occasion. A preliminary version of the topic knowledge measure was reviewed by a professor of medical biochemistry at the University of Oslo who was not part of the project, which resulted in only minor modifications to the response alternatives of a few items. Sample items from the topic knowledge measure are displayed in Appendix A. In the larger sample of students with dyslexia from which the four participants were selected, the internal consistency reliability (Kuder - Richardson 20) for scores on this measure was .62. 


\subsubsection{Working memory measure.}

Working memory was measured using a Norwegian adaptation of Swanson and Trahan's (1992) Working Memory Span Task (Braasch, Bråten, Strøms $\varnothing, \&$ Anmarkrud, 2014). This measure is derived from Daneman and Carpenter's (1980) original Reading Span Test. Twelve sets of unrelated sentences were read aloud with a 2-second interval between each sentence. The sets gradually increased from two to five sentences. Participants were tasked to simultaneously a) answer a comprehension question about an unknown sentence after the final sentence was read, and b) remember the final words from each of the sentences. For each of the 12 trials, participants were awarded 1 point if they correctly answered the comprehension question and one additional point for each of the final words they recalled. If participants failed to answer the comprehension question correctly, they did not receive any points for that set regardless of how many final words they recalled. Internal consistency reliability (Cronbach's $\alpha$ ) for scores on this measure in the larger sample of students with dyslexia from which the four participants were selected was .73.

\subsubsection{Multiple source integration task.}

Multiple source integration was assessed by asking the four participants to respond orally to two openended questions modelled on the integrative short essay tasks used by Rukavina and Daneman (1996) to measure students' understanding of a controversial scientific issue. Of note is that this approach also has been used effectively in several previous studies of multiple source integration (e.g., Barzilai \& Ka'adan, 2017; Bråten, Anmarkrud, Brandmo, \& Strømsø, 2014; Ferguson \& Bråten, 2013).The first question was, "Could you explain the relationship between sun exposure, health, and illness?" The second question was, "Could more than one view on the relationship between sun exposure, health, and illness be correct? Yes or no? If yes, why? If no, why not?" Following Rukavina and Daneman (1996), we considered our first question to indirectly require participants to integrate different perspectives across web pages and representations, or, at least, to consider each perspective's claims and explanations. Our second question was considered to directly require participants to pit perspectives against each other, measuring how well they could reason about the issue in terms of the claims and explanations presented across web pages and representations.

The oral responses were audio-taped and transcribed before they were scored. Following Andresen et al. (2019), the responses were scored in three steps. In the first step, we coded responses to both questions based on the extent to which participants integrated the two main perspectives represented in the materials (i.e., sun exposure is healthy vs. sun exposure is harmful), regardless of the web pages and representations they drew upon in their responses. On the indirect integrative question, participants could obtain scores between 0 and 5. A score of 0 was given for no response or for irrelevant information. A score of 5 was given for mentioning the two main perspectives and providing elaborate explanations or reasons for both perspectives as well as relating the two perspectives to each other by comparing and/or contrasting them and trying to reconcile them. Inter-rater reliability was established in the larger sample from which the four participants were selected. In this process, the first and second authors independently scored a random selection of 50\% of participant responses to the first question, initially agreeing on $80 \%$ and resolving all disagreements through discussion. On the direct integrative question, we first coded whether participants recognized that the main perspectives were not mutually exclusive and might be reconciled (i.e., whether participants answered "yes" or "no" to the question). Second, we coded to what extent participants could explain and reconcile the two perspectives (i.e., when they answered "yes") and to what extent they could select one of the perspectives and provide explanation or reason for that perspective (i.e., when they answered "no"). Again, scores could range from 0 to 5 . A score of 0 was given when participants answered "no" to the question without providing any further justification for their answer. A score of 5 was given when participants answered "yes" to the question, mentioned the two perspectives, provided elaborate explanations or reasons for both, and related the two perspectives to each other by explaining how they may be reconciled. Again, the reliability of the coding was established in the larger sample from which the participants were selected. The first and second authors independently scored a random selection of $50 \%$ of the answers to the second question, initially agreeing on $83 \%$ and resolving all disagreements through discussion. Participants' scores on the two integrative questions were collapsed, which means that their scores after this step could range from 0 to 10 . Table 4 presents the entire coding system used for scoring the oral responses in the first step. 
Table 4

Coding system used in the first step of the scoring of the oral responses

Question 1: Could you explain the relationship between sun exposure, health, and illness?

$0 \quad$ No response or irrelevant information.

1 Mentioning one or two perspectives (sun exposure is harmful and sun exposure is healthy, respectively) without explanation.

2 Mentioning one or two perspectives with explanation (e.g., sun exposure is harmful due to the increased risk of skin cancer) for one or both perspectives.

3 Mentioning two perspectives with elaborated explanation for one (e.g., explaining that sun exposure may cause skin cancer and elaborating on different types of cancer that different types of ultraviolet radiation may cause, or explaining that sun exposure may increase vitamin D production and elaborating on different types of cancer that ultraviolet radiation may protect against, respectively) of the perspectives.

4 Mentioning two perspectives with elaborated explanation for both perspectives.

5 Mentioning the two perspectives and providing elaborate explanations or reasons for both as well as relating the two perspectives to each other by comparing and/or contrasting them and trying to reconcile them by demonstrating that they must not be mutually exclusive.
Question 2: Could more than one view on the relationship between sun exposure, health, and illness be correct? Yes or no? If yes, why, if no, why not?

No response, irrelevant information, or only answering "no" to the first question.

Answering "no" to the first question, and selecting one of the perspectives (i.e., stating a position on the issue) without explanation or reason.

or

Only answering "yes" to the first question.

Answering "no" on the first question, and selecting one of the perspectives and providing explanation or reason for this.

or

Answering "yes" to the first question, and in addition mentioning the two perspectives.

Answering "no" on the first question, and selecting one of the perspectives and providing elaborated explanation or reason for this.

$$
\text { or }
$$

Answering "yes" to the first question, mentioning the two perspectives and providing explanation or reason for one or both.

Answering "yes" to the first question, mentioning the two perspectives and providing elaborate explanation or reason for one or both.

Answering "yes" to the first question and mentioning the two perspectives and providing elaborate explanations or reasons for both as well as relating the two perspectives to each other by explaining how they may be reconciled.

In the second step, we assessed the extent to which participants drew on information from the three different web pages and the different types of representations on each web page (i.e., text, video, and picture) when constructing their oral responses to the two questions. Because the main idea units of each representation were unique, we could trace an idea unit included in an oral response back to a particular representation on a particular web page. Inter-rater reliability of this coding also was established in the larger sample by the first and second authors who independently coded a random selection of $50 \%$ of the responses to both questions and initially agreed on the origin of $85 \%$ of the idea units. All disagreements were resolved through discussion. 
In the second step, participants could obtain scores between 1 and 2.98. In addition to a constant of 1 , participants were awarded a score of 0.33 for each web page and a score of 0.11 for each representation (i.e., text, video, or picture) that they used in their responses. For example, a participant who included idea units from the text and the video on the first web page would obtain a score of 0.33 for the web page and a score of 0.11 each for the text and the video, so this participant's score would be 1.55 (including the constant). If this participant additionally drew on the video on the second web page, he or she would obtain a score of 0.33 for that web page and 0.11 for that video, resulting in a score of 1.99 (including the constant). We awarded a score of 0.33 for each web page and a score of 0.11 for each representation because we considered the entire web site to consist of three parts (i.e., web pages), which were again divided into three representations.

In the third step, we computed each participant's total multiple source integration score by multiplying the participant's score from the first and second steps. In this way, we considered both the integration of the main perspectives (step one) and the coverage of the learning materials (step two) when assessing multiple source integration. Thus, on the multiple source integration task, participants could obtain a maximum score of 29.8 (i.e., $10 \times 2.98$ ). The reason we added a constant of 1 to each participant's score in the second step was to avoid any participant obtaining a total multiple source integration score that was lower than the score obtained in step one.

\subsubsection{Apparatus and analysis of eye-tracking data.}

When working with the learning materials, gaze data were collected by means of a Tobii X2-60 eyetracking device. The Tobii X2-60 is a screen-based eye tracker that records gaze data at a sampling rate of 60 $\mathrm{Hz}$. Data collection took place in a quiet room, and direct sunlight to the screen and the student's head was restricted to avoid distorting reflections. Students sat approximately $60 \mathrm{~cm}$ from the screen, which was a T540P Lenovo laptop with a 15.6 " monitor and 1920 x 1080 resolution. A nine-point calibration task was used to ensure reliable eye-tracking. The process was repeated until the average deviation dropped below $0.5^{\circ}$. Eyetracking data were analyzed with two different approaches. First, participants' patterns of processing were examined with regard to sequence of processing (linear vs. nonlinear processing patterns) and time spent on the various web pages and representations. Second, we performed finer grained analyzes of eye movements during the reading of the texts on the three web pages. Eye-tracking data were analyzed by means of Tobii Studio software. Specifically, we established text paragraphs as the main Areas of Interest (AOI). Within these, we examined the number of fixations, average duration of fixations (measured in milliseconds), and percentage of regressions (saccadic movements to the left, excluding carriage returns). The first time participants read a paragraph was defined as first-pass reading, while any subsequent reread was considered second-pass reading. In the reading literature, higher average fixation duration and a high percentage of regressions are considered indicators of comprehension difficulties (Rayner, Chace, Slattery, \& Ashby, 2006; Schotter, Tran, \& Rayner, 2014).

\subsubsection{Follow-up interview.}

Finally, when participants had finished working with the learning materials and responded to the postreading measures, we replayed the recordings of their eye movements and used these recordings as stimuli to gain insight into whether there were any deliberate reasons for their processing patterns when working with the learning materials. The main topic of these follow-up interviews was the order in which the different web pages and representations where processed and whether the observed processing pattern was representative of how they would typically approach a web page in an academic setting. The follow-up interviews were transcribed, and the various utterances were given a time stamp making it possible to connect an utterance to an incident in the recordings of the eye movements. 


\subsection{Procedure}

Data collection took place in two different sessions, approximately two weeks apart. The first author collected all data in participants' home schools either during the school day or directly afterwards. All instructions, questionnaire items, and questions were read aloud to the participants while they had their own printed copies in front of them. This procedure was followed to reduce the effects of participants' reading difficulties on the various measures.

In the first session, the topic knowledge and working memory measures were individually administered in that order. This session lasted approximately 40 minutes. In the second session, participants individually studied the three web pages on a laptop (see above) with the following instruction read aloud: "Sun exposure and health is a topic of current interest. Imagine that you are supposed to hold an oral presentation on this topic for your fellow students. Here are three web pages you can use to prepare the presentation. You may have 30 minutes studying these three pages; please do not take any notes. You can move between the pages as much as you would like and read them in the order that you choose". When finished working on the three web pages, the participants responded to the topic knowledge measure for a second time before answering the oral multiple source integration task. Finally, the follow-up interview was conducted. Participants were given a gift certificate of 300 NOK (approximately 35 US \$) and were offered an individual course in strategic Internet reading as a reward for their participation. This study was carried out in accordance with the recommendations of The Norwegian National Research Ethics Committees. The protocol was approved by the Norwegian Centre for Research Data. In Norway, the Norwegian Centre for Research Data functions as a national ethics committee approving all studies within the social sciences. All subjects as well as their parents gave written informed consent for participation in the study.

\section{Results}

To address the first research question regarding possible variations in the processing patterns, we used eye tracking to examine their processing of the web pages and representations. We also performed a more detailed analysis of eye movements during text reading, focusing on differences among participants regarding number of fixations, fixation duration, and regressions.

Figure 1 displays the processing pattern of the four participants when working with the learning materials in the second session. One difference that could be observed concerned how they initially explored the web pages. Participant 3 started the session by using 20 seconds to quickly click through all three pages, before returning to the first page and going through the three web pages more thoroughly. Participant 4 , on the other hand, went straight to page one, going through this page before moving to page two and page three. On each web page, both Participant 1 and Participant 2 started with the text before moving on to the video and the picture, in that order.

A second difference was overall processing time, with Participant 1 spending a total of 23 minutes and the other three spending between 6 minutes and 30 seconds and 7 minutes and 45 seconds on the three web pages. Interestingly, the time Participant 1 spent on reading the texts on the three web pages (15 minutes) constituted the difference in total processing time between Participant 1 and the other participants.

A third observable difference between the participants was the sequence of processing the web pages, specifically the degree of linearity. The processing patterns of Participant 3 and Participant 4 can be categorized as linear in the sense that they both processed the various representations in the order in which they appeared on the web pages (i.e., video, text, and picture). Although the processing patterns of these two students may look identical on a surface level, there were important differences on a more detailed level. Thus, Participant 3 always started out by reading the lead paragraph explaining the content of the page before going through each web page in a linear pattern. Participant 4 skipped the lead paragraph on all pages and went directly to the video before examining the text and picture in a linear pattern on every page. In the follow-up 
interview, Participant 3 said that this quick examination of the three web pages was a deliberate strategy used to get an overview of the content of the web pages. When asked about the processing order of the representations in the follow-up interview, both Participant 3 and Participant 4 explained that they believed that those who make web pages probably have a reason for the design of a page; therefore, they just processed the representations in the order in which they appeared on each web page.

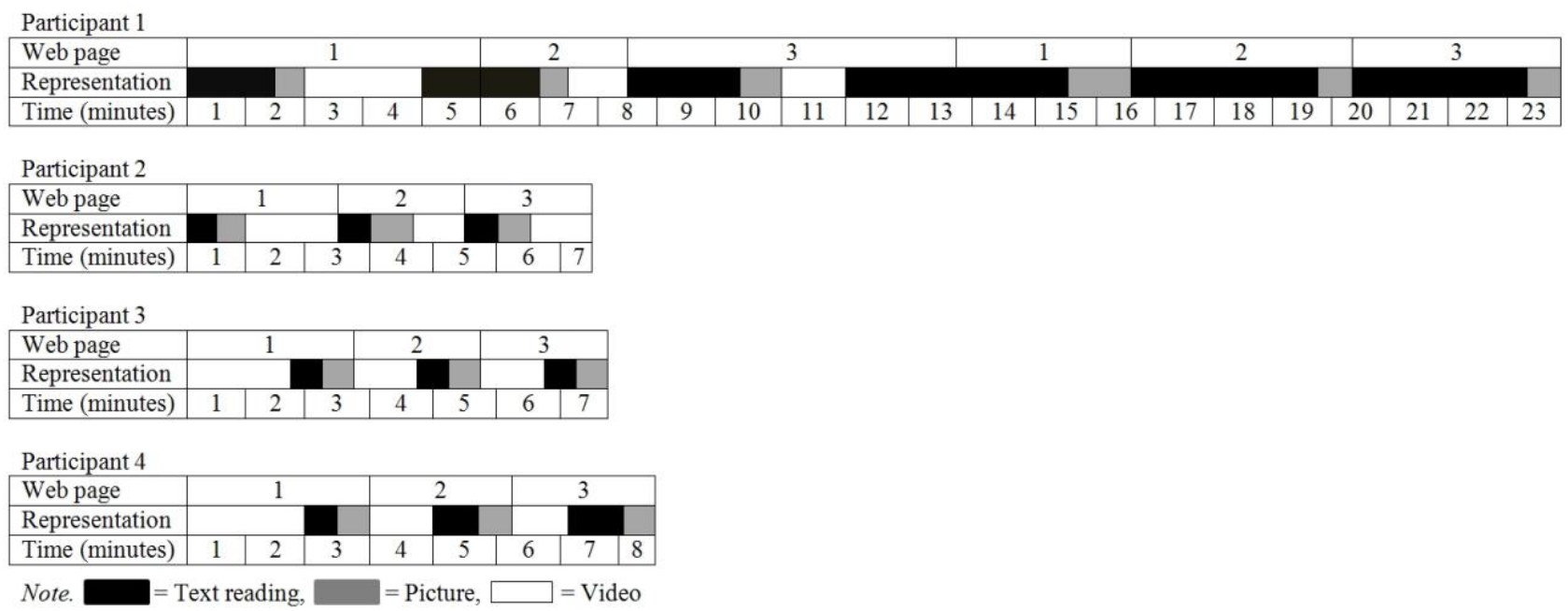

Figure 1. Processing patterns of the four participants on the three web pages

The processing patterns of Participant 1 and Participant 2 can be described as nonlinear because they did not process the representations in the order in which they appeared on the web pages. A noteworthy difference between Participant 1 and Participant 2 was that the former systematically went back and reread the text and re-examined the pictures on each web page after the initial processing of the site. Although, as seen from the processing patterns, they both prioritized the text (i.e., read the text first), their reasons for this were different. Participant 1 explained in the follow-up interview that reading the text first was done deliberate to get some knowledge of the content before watching the video; a strategic activity used to maximize the comprehension of the video. Participant 1 applied this strategy on all three web pages. Participant 2, on the other hand, expressed that the text was usually the representation that contained the key information on a web page, and, therefore, Participant 2 would always start with the text when entering a web page. This participant also gave another strategic reason for such a processing pattern during the follow-up interview. Due to the reading difficulties, Participant 2 sometimes experienced that "things were unclear" after the reading of a text on a web page, hoping to clarify misunderstandings by watching a video or looking at pictures if such representations were available on a web page.

Regarding the second research question, we examined whether processing patterns were related to differences among participants with respect to working memory capacity, reading skills, and topic knowledge, as well as to their post-reading performances on the topic knowledge measure and the multiple source integration task. 
Table 5

Number of fixations, percentage of regressions, and fixation duration during reading

\begin{tabular}{|c|c|c|c|c|}
\hline & $\begin{array}{c}\text { Participant } \\
1\end{array}$ & $\begin{array}{l}\text { Participant } \\
2\end{array}$ & $\begin{array}{c}\text { Participant } \\
3\end{array}$ & $\begin{array}{c}\text { Participant } \\
4\end{array}$ \\
\hline \multicolumn{5}{|l|}{ Web page 1} \\
\hline Number of fixations & $\begin{array}{l}1^{\text {st }} \text { pass } / 2^{\text {nd }} \text { pass } / \text { Total } \\
110 / 195 / 305\end{array}$ & 50 & 48 & 50 \\
\hline$\%$ Regressions & $\begin{array}{l}1^{\text {st }} \text { pass } / 2^{\text {nd }} \text { pass } / \text { Total } \\
25.45 / 27.18 / 26.55\end{array}$ & 20 & 20.83 & 32 \\
\hline \multicolumn{5}{|l|}{ Web page 2} \\
\hline Number of fixations & $\begin{array}{l}1^{\text {st }} \text { pass } / 2^{\text {nd }} \text { pass } / \text { Total } \\
158 / 181 / 339\end{array}$ & 78 & 59 & 104 \\
\hline$\%$ Regressions & $\begin{array}{l}1^{\text {st }} \text { pass } / 2^{\text {nd }} \text { pass } / \text { Total } \\
31.65 / 35.36 / 33.63\end{array}$ & 30.77 & 10.17 & 40.38 \\
\hline \multicolumn{5}{|l|}{ Web page 3} \\
\hline Number of fixations & $\begin{array}{l}1^{\text {st }} \text { pass } / 2^{\text {nd }} \text { pass } / \text { Total } \\
135 / 522 / 657\end{array}$ & 60 & 72 & 94 \\
\hline$\%$ Regressions & $\begin{array}{l}1^{\text {st }} \text { pass } / 2^{\text {nd }} \text { pass/Total } \\
20 / 36.21 / 32.87\end{array}$ & 25 & 18.05 & 41.49 \\
\hline \multicolumn{5}{|c|}{ 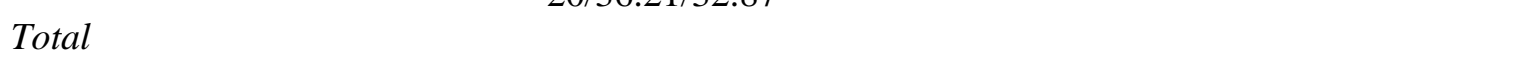 } \\
\hline Number of forward fixations & $\begin{array}{l}1^{\text {st }} \text { pass } / 2^{\text {nd }} \text { pass/Total } \\
298 / 592 / 890\end{array}$ & 139 & 150 & 151 \\
\hline$\%$ Regressions & $\begin{array}{l}1^{\text {st }} \text { pass } / 2^{\text {nd }} \text { pass } / \text { Total } \\
26.05 / 34.08 / 31.59\end{array}$ & 26.06 & 16.20 & 39.11 \\
\hline \multirow[t]{2}{*}{$\begin{array}{l}\text { Average forward fixation } \\
\text { duration }{ }^{1} M(S D)\end{array}$} & $\begin{array}{l}1^{\text {st }} \text { pass } \\
\quad \begin{array}{l}530.70 \\
(368.37)\end{array}\end{array}$ & $\begin{array}{c}199.64 \\
(124.37)\end{array}$ & $\begin{array}{c}190.41 \\
(101.41)\end{array}$ & $\begin{array}{c}310 \\
(186.61)\end{array}$ \\
\hline & $\begin{array}{cc}2^{\text {nd }} \text { pass } & \\
& 421.30 \\
& (283.92) \\
\text { Total } & \\
& 476.00 \\
& (326.14)\end{array}$ & & & \\
\hline Average regression duration ${ }^{1}$ & $1^{\text {st }}$ pass & 177.03 & 202.46 & 302.37 \\
\hline \multirow[t]{3}{*}{$\mathrm{M}(\mathrm{SD})$} & $\begin{array}{c}382.88 \\
(212.40)\end{array}$ & $(84.45$ & 76.10 & $(163.27)$ \\
\hline & $\begin{array}{l}2^{\text {nd }} \text { pass } \\
367.23 \\
(224.10)\end{array}$ & & & \\
\hline & $\begin{array}{cc}\text { Total } & \\
& 375.06 \\
& (218.24)\end{array}$ & & & \\
\hline
\end{tabular}

Note. ${ }^{1}$ Fixation durations are measured in milliseconds. Outlier fixations (defined as participants' mean fixation $+2 S D$ ) are replaced by participants' median fixation.

The results of the eye-tracking analyses are displayed in Table 5, with results corroborating the findings of the EPS assessments regarding the reading levels of the participants. Each participant's average fixation duration (see "Average forward fixation duration" in Table 5) and percentage of regressions across 
the three web pages were compared with the reading of students with normative development (Rayner, Ardoin, \& Binder, 2013) and with a sample of students with dyslexia (Prado, Dubois, \& Valdois, 2007).

Participant 1 read texts at a substantially slower rate (average fixation duration $476 \mathrm{msc}$ ) but did not display more regressions (31.59\% regressions) than what has been reported in children with dyslexia (325 msc, $31 \%$ regressions). Participant 1 was also the only participant who reread all three texts. As can be seen in Table 5, both the 1st and the 2nd pass were characterized by long fixations and many regressions. Participant 4's reading behavior (average fixation duration $310 \mathrm{msc}, 39.11 \%$ regressions) was similar to what has been reported for children with dyslexia. Finally, Participant 2 and Participant 3 read the texts substantially faster (with average fixation duration 200 and $190 \mathrm{msc}$, and with $26.06 \%$ and $16.20 \%$ regressions, respectively), which closely resembles the behaviors typically reported for children without dyslexia of a similar age (average fixation duration 230-250 msc, 22\% regressions) (Rayner et al., 2013). However, previous research has found that the transparency of the orthography can influence fixation time during reading; the deeper the orthography, the longer the fixations (Bahnmueller, Huber, Nuerk, Göbel, \& Moeller, 2016; Rau, Moll, Snowling, \& Landerl, 2015; Van Roy \& Pretorius, 2013). Norwegian is a transparent orthography compared to English or French, and this should be considered when interpreting the reading rates of Participant 2 and Participant 3 in relation to the norms, which are established with English- or French-speaking children.

\subsection{Learning Gain and Multiple Source Integration}

As displayed in Table 6, the participants started out with a similar amount of topic knowledge, with Participant 1 and Participant 3 receiving a score of 4 , which is equivalent to a $z$-score of -1.32 compared to a norm sample of 528 Norwegian 10th and 11th graders without dyslexia (Anmarkrud \& Ferguson, 2011). Please note that all participants in the norm sample responded to the same topic knowledge measure both before and after studying the same information about sun exposure and health as did the four participants in the current study, and that the pre-reading topic knowledge, post-reading topic knowledge, and learning gain of the participants in the current study were compared to the pre-reading topic knowledge, post-reading topic knowledge, and learning gain obtained by the students in the norm sample. Participant 2 and Participant 4 scored 5, which is equivalent to a $\mathrm{z}$-score of -.93 when compared to the norm sample. However, there were differences between the participants with respect to learning gain, indicating the amount of factual knowledge they were able to gain from working with the learning materials. Participant 1 read at a much slower rate than what is often seen among students with dyslexia but reread all texts thoroughly. This participant had a learning gain of 6, ending up with a post-reading topic knowledge score of 10 (z-score -.14). Compared to the norm sample, this is a substantial learning gain, equivalent to a $\mathrm{z}$-score of 1.45. Participant 3 and Participant 4 both ended up with a post-reading topic knowledge score of 9 (z-score -.72), with their learning gains of 5 and 4 equalling z-scores of .99 and .53 , respectively, when compared to the norm sample. Hence, the results indicated that these three participants were all able to extract factual knowledge from the representations and web pages included in the learning materials. However, Participant 2 , who read relatively fast and also displayed relatively low working memory capacity, did not seem to gain much factual knowledge from the learning materials, increasing the topic knowledge score by only one point and ending up with a post-reading topic knowledge score of 6 (z-score -2.48), indicating a relatively small learning gain compared to the norm sample (z-score .86).

On the multiple source integration task, higher scores required that readers integrated information across web pages and representations (i.e., texts, videos, and pictures) into a coherent mental representation of the issue of sun exposure and health. Given a potential maximum score of 29.8, Participant 1 clearly struggled with this task and obtained a score of only 3.76 , which is equivalent to a $\mathrm{z}$-score of -1.76 when compared to a sample of Norwegian 10th graders previously responding to this task (Authors 1). Participant 3 and Participant 4 obtained scores of 5.64 and 9.28, equalling z-scores of -1.46 and -.88, respectively. In contrast, Participant 2 , who gained little factual knowledge, received a multiple source integration score of 16.80 (z-score .35), thus performing above the average of the norm sample. Hence, the results suggested that none of the four participants was able to learn factual knowledge from the three web pages (indicated by the post-reading topic 
knowledge scores) and at the same time construct a coherent mental representation of the issue in question (indicated by the scores on the multiple source integration task). Thus, spending cognitive processing capacity on integrating information across different web pages and representations seemed to have left little capacity for learning factual information from the same web pages and representations, and vice versa.

Table 6

Participant scores on the learning and integration measures

\begin{tabular}{lcccc}
\hline & $\begin{array}{l}\text { Pre-reading topic } \\
\text { knowledge }^{1}\end{array}$ & $\begin{array}{l}\text { Post-reading topic } \\
\text { knowledge }\end{array}$ & Learning gain & $\begin{array}{l}\text { Multiple source } \\
\text { integration score }^{2}\end{array}$ \\
\hline Participant 1 & $4(z$-score -1.32$)$ & $10(z$-score -.14$)$ & $6(z$-score 1.45$)$ & $3.76(z$-score -1.76$)$ \\
Participant 2 & $5(z$-score -.93$)$ & $6(z$-score -2.48$)$ & $1(z$-score -.86$)$ & $16.80(z$-score .35$)$ \\
Participant 3 & $4(z$-score -1.32$)$ & $9(z$-score -.72$)$ & $5(z$-score .99$)$ & $5.64(z$-score -1.46$)$ \\
Participant 4 & $5(z$-score -.93) & $9(z$-score -.72$)$ & $4(z$-score .53$)$ & $9.28(z$-score -.88) \\
\hline
\end{tabular}

Note. ${ }^{1}$ The $z$-scores are based on comparison with the pre-reading topic knowledge, post reading topic knowledge, and learning gain scores of a sample of 528 Norwegian 10th and 11 th graders (Anmarkrud \& Ferguson, 2011). ${ }^{2}$ The z-scores are based on comparison with a sample of 44 Norwegian 10th graders (Andresen et al., 2019).

Table 7

Representations drawn on in the integration task

\begin{tabular}{|c|c|c|c|c|}
\hline & Participant 1 & Participant 2 & Participant 3 & Participant 4 \\
\hline \multicolumn{5}{|l|}{ Web page 1} \\
\hline Video & - & - & - & - \\
\hline Text & - & - & - & - \\
\hline Picture & - & - & - & Yes \\
\hline \multicolumn{5}{|l|}{ Web page 2} \\
\hline Video & Yes & Yes & Yes & Yes \\
\hline Text & - & - & - & - \\
\hline Picture & - & Yes & - & - \\
\hline \multicolumn{5}{|l|}{ Web page 3} \\
\hline Video & Yes & Yes & Yes & - \\
\hline Text & - & - & . & - \\
\hline Picture & - & Yes & - & Yes \\
\hline
\end{tabular}

Finally, even though the eye-tracking data indicated that the four participants processed all the representations on all the web pages, there was a clear pattern regarding which representations the participants drew on in the multiple source integration task. As displayed in Table 7, none of the participants drew on the text material when answering the multiple source integration task; they all based their oral responses on videos and, to some degree, information from the pictures. Hence, since all the participants processed the texts, the inability to draw on information from the texts in the integrations task could not be ascribed to a lack of processing of the texts, but rather the inability to integrate the information extracted from the texts with information from other representations across the three web pages. 


\section{Discussion}

The present study examined how four adolescents with dyslexia processed information from multiple representations in a digital context and how they learned from and integrated information across different representations and web pages. Our first research question concerned differences in processing patterns and whether differences in processing patterns represented differences with respect to deliberate strategic activity. While all the participants provided reasons for the strategic approaches they chose when working with the learning materials, there seemed to be differences regarding the sophistication of these strategic approaches.

Two of the participants, Participant 3 and Participant 4, processed the various representations in the same order as they appeared on the web pages, with the rationale for this linear processing approach being that those who made web pages probably had good reasons for the order in which the representations appeared. Both Participant 1 and Participant 2, on the other hand, started with the text before processing the graphic representations. Previous research has revealed that students with dyslexia may be aware of their reading problems but seem to have a limited strategic repertoire to compensate for these difficulties (Furnes \& Norman, 2015). Moreover, studies conducted with traditional paper-based reading have consistently found differences between students with and without reading difficulties regarding knowledge about which strategies to use and when to use them (e.g., Baker \& Beall, 2009; Furnes \& Norman, 2015; Roeschl-Heils, Schneider, \& van Kraayenoord, 2003). In their review of the literature, Anderson and Ambruster (1984) reported that, compared to students without reading difficulties, students with reading difficulties to a lesser degree planned their reading ahead, integrated information, and reread text when they noticed comprehension problems. Hence, it is interesting that only one of the participants (Participant 2) explained a strategic approach by referring to the reading difficulties. This participant thus read the text first, and then examined pictures and videos to clarify misunderstandings that might have arisen while reading due to the reading difficulties. Although Participant 1 did not verbalize any particular strategic reason for the meticulous reading, and rereading, of the texts on the three web pages, it is conceivable that this approach reflected the experience as a struggling reader and reasoning about what could do to compensate for the difficulties. Hence, inconsistent with what we expected, a strategic approach to the learning materials was taken by the two participants who started with text before moving towards the graphic representations, in accordance with a text-to-picture processing approach (Hegarty \& Just, 1993; Mason et al., 2017). The prioritization of text, regarding both the time spent with text and the decision to process text first, can also reflect the text superiority effect (e.g., Corriveau, Einav, Robinson, \& Harris, 2014; Einav, Robinson, \& Fox, 2012; Eyden, Robinson, Einav, \& Jaswal, 2013), which implies that children tend to put more trust and emphasis on information from written information compared to other types of information, especially in an academic context. The approaches of Participant 3 and Participant 4 can be described as less sophisticated and more passive. Simply following the order of the web pages in a linear approach can reflect a type of "outsourcing" of the decisions regarding how to work with the learning materials to those who made the web pages.

Participants 2 and 3 read through the texts on the web pages quickly, as compared to what has been established as standards for students with dyslexia (Prado et al., 2007; Rayner et al., 2013). There are several reasons why one should be careful in interpreting this relatively fast reading pace as reflective of good word reading skills. First, the oft-cited standards are based on readers with dyslexia who are younger than those who participated in our study. Second, previous research has found that the transparency of the orthography can influence fixation duration during reading. The fact that Norwegian is a relatively transparent orthography compared to the orthographies within which the standards have been established could be a reason for the slight mismatch between our reading data and the established standards. There are currently no standards for average fixation duration, number of fixations, or amount of regressions based on reading in Norwegian. Third, previous research indicates that reading on a screen in and of itself can lead to a faster reading pace than reading on paper (e.g., Trakhman, Alexander, \& Berkowitz, in press; Van de Vijver \& Harsveld, 1994).

Our second research question concerned the relationship between processing patterns, individual differences in reading abilities and working memory, and learning and integration in a digital multimedia context. The results showed that three of the participants (1,3, and 4) had substantial learning gains, also when 
compared to the learning gains of a norm sample of students without dyslexia. Hence, these three participants were able to learn factual knowledge from representations and web pages, and this knowledge was sufficient to answer post-reading questions in a multiple-choice format. However, these participants were to a very limited degree able to integrate information across representations and web pages into a coherent mental representation that reconciled the opposing perspectives covered in the learning materials. Participant 2 , on the other hand, received a relatively good score on the integration task, also when compared to a norm sample previously responding to this task; however, this participant ended up with a small learning gain, both compared to the other participants in this case study and to the norm sample.

As previously described, learning multimedia materials can place a high demand on the capacitylimited working memory system, and multimedia learning therefore is expected to be a challenge for students with dyslexia because they often have working memory problems. One plausible interpretation of our results is that none of the participants were able to learn information on a propositional level, necessary to answer the multiple-choice questions, and at the same time aggregate the main ideas from the representations and web pages into an integrated understanding of the issue. Thus, it seemed that for these participants, the interaction with the multimedia materials resulted in an "either - or" learning outcome; either the details or the bigger picture, but not both. Presumably, this result is due to the combination of reduced working memory capacity and word reading problems, with reading putting too heavy a load on an already limited working memory and leaving too little working memory capacity to both remember detailed information on a propositional level and integrate information (Anmarkrud et al., 2018; Hulme \& Snowling, 2009; Melby-Lervåg et al., 2012). Accordingly, in previous research on paper-based reading, it has been found that both word recognition and comprehension processes compete for working memory capacity (e.g., Stanovich, 1986). However, this study does not allow us to draw conclusions about whether it is dyslexia or limited working memory capacity that is causing the integration difficulties.

In contrast to our results, as well as what has been found in previous research (e.g., Alty et al., 2006; Beacham \& Alty, 2006; MacCullagh et al., 2017), Knoop-van Campen and colleagues (2018) did not find that readers with dyslexia had difficulties integrating information across different representations compared to peers without dyslexia. One likely explanation for inconsistent results in research on multimedia learning among students with dyslexia is the age of participants. The participants in Knoop-van Campen and colleagues' (2018) study were 11-year-old children, while the participants in this and other studies (Alty et al., 2006; Beacham \& Alty, 2006; MacCullagh et al., 2017) have been university students or adolescents in uppersecondary school. Among 11-year-old children, including children with dyslexia and their typically developing peers, working memory is not yet fully developed (Schneider, 2011). Hence, similarity in working memory capacity in the two groups (i.e., students with and without dyslexia) could have resulted in a lack of difference in multimedia learning.

The large learning gain of Participant 1 also requires some explanation. Despite a very limited working memory capacity and severe reading difficulties, Participant 1 ended up with the largest learning gain among the four participants, a learning gain that was also well above the mean learning gain of the norm sample consisting of students without dyslexia. Knoop-van Campen and colleagues (2018) found that self-paced work with learning materials allowed the participants with dyslexia in their study to spend the time necessary to learn the materials properly. Thus, those authors found that the participants with dyslexia used significantly more time with the learning materials in the text condition compared to the control group, but this extra time washed out the expected differences in learning. In line with this, Participant 1's slow and meticulous processing and reprocessing of the materials seem to have compensated for the shortcomings regarding working memory capacity and reading abilities compared to the other three participants.

Finally, although eye-tracking data revealed that all the participants processed all representations on all pages, it is intriguing that none of the participants drew on the text material in their answers on the integration task. They were, however, able to draw on information from the text when answering the multiplechoice questions. This implies that keeping information from the texts in working memory, and at the same time integrating this information with information from the other representations, seems to be a major challenge for readers with dyslexia. It should be noted that we used a portable eye-tracker without a chin rest 
with a sampling rate of $60 \mathrm{~Hz}$, which is a somewhat lower sampling rate than the current standard in reading research. Albeit being a limitation of the present study, the relatively large areas of interest (i.e., paragraphs) used in the analyses of eye movements make it unlikely that the sampling rate had a large impact on the quality of the data.

\section{Conclusion}

Our comparative case study indicates that students with dyslexia may approach conflicting web pages containing various representations in different ways. Additionally, while they may process information strategically to improve their learning, they may fail to integrate information across different web pages and representations. To the best of our knowledge, this is the first study of dyslexic readers' integration of information across representations and web pages. The few studies that exist on the online reading of students with dyslexia have focused more on the learning outcomes of Internet reading (Castek et al., 2011), Internet reading as a community of practice (Henry et al., 2012), dyslexia-friendly interfaces (McCarthy \& Swierenga, 2010), and the difference between reading printed and digital text (Schneps, Thomson, Chen, Sonnert, \& Pomplum, 2013). Hence, knowledge about how readers with dyslexia process information in a digital multimedia context is essentially lacking. It should be noted that this lack of research makes it difficult to draw firm conclusions regarding readers with dyslexia based on previous work, since this group of readers is almost invisible in research on information processing in multimedia contexts. However, this study brings together two research fields that have traditionally been kept separate in research and theory, that is, the study of dyslexia and the study of learning in a multimedia environment. In the present information society, where the vast majority of adolescents, including those with dyslexia, use multimedia materials such as the Internet as an important information source in their school work, this study represents a timely integration of important areas of research that, hopefully, will inspire much further work.

\section{Keypoints}

Students with dyslexia worked with multiple web pages and representations

Eye-tracking and interviews showed differences in processing and strategy use

Processing was related to individual differences and learning and integration

Learning and integrating information at the same time were problematic

\section{Acknowledgments}

Thanks are due to Shane Colvin and Arild Moland for help in creating the learning materials.

\section{References}

Abtahi, M.S. (2012). Interactive multimedia learning object (IMLO) for dyslexic children. Procedia - Social and Behavioral Sciences, 47, 1206-1210. doi:10.1016/j.sbspro.2012.06.801

Afflerbach, P., Pearson, P.D., \& Paris, S.G. (2008). Clarifying differences between reading skills and reading strategies. The Reading Teacher, 61, 364-373. doi:10.1598/RT.61.5.1 
Ainsworth, S. (2018). Multiple representations and multimedia learning. In F. Fischer, C.E. Hmelo-Silver, S.R. Goldman, \& P. Reiman (Eds.), International handbook of the learning sciences (pp. 96-105). New York: Routledge.

Alty, J. L., Al-Sharrah, A., \& Beacham, N. (2006). When humans form media and media form humans: An experimental study examining the effects different digital media have on the learning outcomes of students who have different learning styles. Interacting with Computers, 18, 891-909. doi:10.1016/j.intcom.2006.04.002

Anderson, T.H., \& Ambruster, B.B. (1984). Studying. In P.D. Pearson, M. Kamil, R. Barr, \& P. Rosenthal (Eds.), Handbook of reading research (1st ed., pp. 657-679). White Plains, NY: Longman.

Andresen, A., Anmarkrud, Ø., \& Bråten, I. (2019). Investigating multiple source use among students with and without dyslexia. Reading and Writing, 32, 1149-1174. https://doi.org/10.1007/s11145-0189904-z

Anmarkrud, Ø., Brante, E.W., \& Andresen, A. (2018). Potential processing challenges of Internet use among readers with dyslexia. In J.L.G. Braasch, I. Bråten, \& M.T. McCrudden (Eds.), Handbook of multiple source use (pp. 117-132). New York: Routledge.

Anmarkrud, Ø., \& Ferguson, L.E. (2011). Working memory and topic knowledge of Norwegian 10th and 11th graders. Unpublished data set. Oslo: Faculty of Educational Sciences, University of Oslo.

Austin, K.A. (2009). Multimedia learning: Cognitive individual differences and display design techniques predict transfer learning with multimedia learning modules. Computers \& Education, 53, 1339-1354. doi:10.1016/j.compedu.2009.06.017

Avons, S.E., \& Hanna, C. (1995). The memory-span deficit in children with specific reading-disability - is speech rate responsible? British Journal of Developmental Psychology, 13, 303-311. doi: 10.1111/j.2044-835X.1995.tb00681.x

Ayres, P., \& Sweller, J. (2014). The split-attention principle in multimedia learning. In R.E. Mayer (Ed.), The Cambridge handbook of multimedia learning (pp. 206-226). New York: Cambridge University Press.

Azevedo, R., \& Cromley, J.G. (2004). Does training on self-regulated learning facilitate students' learning with hypermedia? Journal of Educational Psychology, 96, 523-535. DOI: 10.1037/00220663.96.3.523

Baddeley, A. (1995). Working memory. Oxford: Clarendon Press.

Baddeley, A.D. (2000). The episodic buffer: A new component of working memory? Trends in Cognitive Science, 4, 417-423. doi: 10.1016/S1364-6613(00)01538-2

Bahnmueller, J., Huber, S., Nuerk, H.C., Göbel, S.M., \& Moeller, K. (2016). Processing multi-digit numbers: A translingual eye-tracking study. Psychological Research, 80, 422-433. doi: $10.1007 / \mathrm{s} 00426-015-0729-\mathrm{y}$

Baker, L., \& Beall, L.C. (2009). Metacognitive processes and reading comprehension. In S.E. Israel \& G.G. Duffy (Eds.), Handbook of research on reading comprehension (pp. 373-388). New York: Routledge.

Barbosa, T., Miranda, M.C., Santos, R.F., \& Bueno, O.F.A. (2009). Phonological working memory, phonological awareness, and language in literacy difficulties in Brazilian children. Reading and Writing, 22, 201-218. doi: 10.1007/s11145-007-9109-3

Barzilai, S., \& Ka'adan, I. (2017). Learning to integrate divergent information sources: The interplay of epistemic cognition and epistemic metacognition. Metacognition and Learning, 12, 193-232. doi: 10.1007/s11409-016-9165-7

Beacham, N.A., \& Alty, J.L. (2006). An investigation into the effects that digital media can have on the learning outcomes of individuals who have dyslexia. Computers \& Education, 47, 74-93. doi: 10.1016/j.compedu.2004.10.006

Berninger, V. W., Raskind, W., Richards, T., Abbott, R., \& Stock, P. (2008). A multidisciplinary approach to understanding developmental dyslexia within working-memory architecture: Genotypes, phenotypes, brain, and instruction. Developmental Neuropsychology, 33, 707-744. doi: $10.1080 / 87565640802418662$ 
Bishop, D.V.M., \& Snowling, M.J. (2004). Developmental dyslexia and specific language impairment: Same or different? Psychological Bulletin, 130, 858-886. doi: 10.1037/0033-2909.130.6.858

Björnsson, C. H. (1968). Läsbarhet [Readability]. Stockholm: Liber.

Borella, E., Carretti, B., \& Pelegrina, S. (2010). The specific role of inhibition in reading comprehension in good and poor comprehenders. Journal of Learning Disabilities, 43, 541-552. doi: $10.1177 / 0022219410371676$

Braasch, J.L.G., Bråten, I., Strømsø, H.I., \& Anmarkrud, Ø. (2014). Incremental theories of intelligence predict multiple document comprehension. Learning and Individual Differences, 31, 11-20. doi: 10.1016/j.lindif.2013.12.012

Bråten, I., Anmarkrud, Ø., Brandmo, C., \& Strøms $\varnothing$ H.I. (2014). Developing and testing a model of direct and indirect relationships between individual differences, processing, and multiple-text comprehension. Learning and Instruction, 30, 9-24. doi: 10.1016/j.learninstruc.2013.11.002

Bråten, I., Braasch, J.L.G., \& Salmerón, L. (in press). Reading multiple and non-traditional texts: New opportunities and new challenges. In E.B. Moje, P. Afflerbach, P. Enciso, \& N.K. Lesaux (Eds.), Handbook of Reading Research (Vol. V). New York: Routledge.

Butcher, K.R. (2014). The multimedia principle. In R.E. Mayer (Ed.), The Cambridge handbook of multimedia leraring (2nd ed., pp. 174-205). New York: Cambridge University Press.

Campbell, S. (2012). Comparative case study. In A.J. Mills, G. Durepos, \& E. Wiebe (Eds.), Encyclopedia of case study research (pp. 175-176). Thousand Oaks, CA: Sage.

Castek, J., Zawilinski, L., McVerry, J.G., O'Byrne, W.I., \& Leu, D.J. (2011). The new literacies of online reading comprehension: New opportunities and challenges for students with learning difficulties. In C. Wyatt-Smith, J. Elkins, \& S. Gunn (Eds.), Multiple perspectives on difficulties in learning literacy and numeracy (pp. 91-110). New York: Springer.

Chan, E., \& Unsworth, L. (2011). Image-language interaction in online reading environments: Challenges for students' reading comprehension. Australian Educational Researcher, 38, 181-202. doi: 10.1007/s13384-011-0023-y

Cho, B.-Y., \& Afflerbach, P. (2017). An evolving perspective of constructively responsive reading comprehension strategies in multilayered digital text environments. In S.E. Israel (Ed.), Handbook of research on reading comprehension (2nd ed., pp. 109-134). New York: Guilford.

Cho, B.-Y., Afflerbach, P., \& Han, H. (2018). Strategic processing in accessing, comprehending, and using multiple sources online. In In J.L.G. Braasch, I. Bråten, \& M.T. McCrudden (Eds.), Handbook of multiple source use (pp. 133-150). New York: Routledge.

Cho, B.-Y., Woodward, L., \& Li, D. (2017). Examining adolescents' strategic processing during online reading with a question generating task. American Educational Research Journal, 54, 691-724. doi: $10.3102 / 0002831217701694$

Clark, J.M., \& Paivio, A. (1991). Dual coding theory and education. Educational Psychology Review, 3, 149-210. doi: 10.1007/BF01320076

Corriveau, K.H., Einav, S., Robinson, E.J., \& Harris, P.L. (2014). To the letter: Early readers trust printbased over oral instructions to guide their actions. British Journal of Developmental Psychology, 32, 345-358. doi: 10.1111/bjdp.12046

Cuevas , H.M., Fiore, S.M., \& Oser, R.L. (2002). Scaffolding cognitive and metacognitive processes in low verbal ability learners: Use of diagrams in computer based training environments. Instructional Science, 30, 433-464. doi: 10.1023/A:1020516301541

Daneman, M., \& Carpenter, P.A. (1980). Individual differences in working memory and reading. Journal of Verbal Learning and Verbal Behavior, 19, 450-466. doi: 10.1016/S0022-5371(80)90312-6

de Olivera, D.G., da Silva, P.B., Dias, N.M., Sebra, A.G., \& Macedo, E.C. (2014). Reading component skills in dyslexia: Word recognition, comprehension, and processing speed. Frontiers in Psychology, 5: 1339. doi: 10.3389/fpsyg.2014.01339

DeSchryver, M. (2015). Higher order thinking in an online world: Toward a theory of web-mediated knowledge synthesis. Teachers College Record, 116, 1-44. http://www.tcrecord.org ID Number: 17692 
Einav, S., Robinson, E.J., \& Fox, A. (2012). Take it as read: Origins of trust in knowledge gained from print. Journal of Experimental Psychology, 114, 262-274. doi: 10.1016/j.jecp.2012.09.016

Eitel, A., \& Scheiter, K. (2015). Picture or text first? Explaining sequence effects when learning with pictures and text. Educational Psychology Review, 27,153-180. doi: 10.1007/s10648-014-9264-4

Eitel, A., Scheiter, K., \& Schüler, A. (2013). How inspecting a picture affects processing of text in multimedia learning. Applied Cognitive Psychology, 27, 451-461. doi: 10.1002/acp.2922

Eitel, A., Scheiter, K., Schüler, A., Nyström, M., \& Holmqvist, K. (2013). How a picture facilitates the process of learning from text: Evidence for scaffolding. Learning and Instruction, 28, 48-63. doi: 10.1016/j.learninstruc.2013.05.002

Eyden, J., Robinson, E.J., Einav, S., \& Jaswal, V.K. (2013). The power of print: Children's trust in unexpected printed suggestions. Journal of Experimental Child Psychology, 116, 593-608. doi: 10.1016/j.jecp.2013.06.012

Fenesi, B., Kramer, E., \& Kim, J.A. (2016). Split-attention and coherence principles in multimedia instruction can rescue performance for learners with lower working memory capacity. Applied Cognitive Psychology, 30, 691-699. doi: 10.1002/acp.3244

Ferguson, L.E., \& Bråten, I. (2013). Student profiles of knowledge and epistemic beliefs: Changes and relations to multiple-text comprehension. Learning and Instruction, 25, 49-61. doi: 10.1016/j.learninstruc.2012.11.003

Fischbach, A., Könen, T., Rietz, C. S., \& Hasselhorn, M. (2014). What is not working in working memory of children with literacy disorders? Evidence from a three-year-longitudinal study. Reading and Writing, 27, 267-286. doi: 10.1007/s11145-013-9444-5

Follmer, D. J. (2018). Executive function and reading comprehension: A meta-analytic review. Educational Psychologist, 53, 42-60. doi: 10.1080/00461520.2017.1309295

Fox, E., \& Alexander, P.A. (2017). Text and comprehension. In S.E. Israel (Ed.), Handbook of research on reading comprehension (2nd ed., pp. 335-352). New York: Guilford.

Furnes, B., \& Norman, E. (2015). Metacognition and reading: Comparing three forms of metacognition in normally developing readers and readers with dyslexia. Dyslexia, 21, 273-284. doi: 10.1002/dys. 1501

Gathercole, S.E., Alloway, T.P., Willis, C., \& Adams, A.-M. (2006). Working memory in children with reading disabilities. Journal of Experimental Child Psychology, 93, 265-281. doi: 10.1016/j.jecp.2005.08.003

Gerjets, P., Scheiter, K., Opfermann, M., Hesse, F.W., \& Eysink, T.H. (2009). Learning with hypermedia: The influence of representational formats and different levels of learner control on performance and learning behavior. Computers in Human Behavior, 360-370. doi: 10.1016/j.chb.2008.12.015

Greene, J.A., Moos, D.C., Azevedo, R., \& Winters, F.I. (2008). Exploring differences between gifted and grade-level students' use of self-regulatory learning processes with hypermedia. Computers \& Education, 50, 1069-1083. doi:10.1016/j.compedu.2006.10.004

Harm, M.V., \& Seidenberg, M.S. (1999). Phonology, reading acquisition, and dyslexia: Insights from connectionist models. Psychological Review, 106, 491-528. doi: 10.1037/0033-295X.106.3.491

Hegarty, M., \& Just, M.A. (1993). Constructing mental models of machines from text and diagrams. Journal of Memory and Language, 32,717-742. doi: 10.1006/jmla.1993.1036

Henry, L.A., Castek, J., O'Byrne, W.I., \& Zawilinski, L. (2012). Using peer collaboration to support online reading, writing, and communication: An empowerment model for struggling readers. Reading \& Writing Quarterly, 28, 279-306. doi: 10.1080/10573569.2012.676431

Høien, T. (2014). Logos - Teoribasert diagnostisering av lesevansker [Logos - Theory based assessment of reading difficulties]. Bryne, Norway: Logometrica.

Hulme, C., \& Snowling, M. J. (2009). Developmental disorders of language learning and cognition. Chichester: Wiley-Blackwell.

Irrazabal, N., Saux, G., \& Burin, D. (2016). Procedural multimedia presentations: The effects of working memory and task complexity on instruction time and assembly accuracy. Applied Cognitive Psychology, 30, 1052-1060. doi: 10.1002/acp.3299 
Jeffries, S., \& Everatt, J. (2004). Working memory: Its role in dyslexia and other specific learning disabilities. Dyslexia, 10, 196-214. doi: 10.1002/dys.278

Johnson, C.I., \& Mayer, R.E. (2012). An eye movement analysis of the spatial contiguity effect in multimedia learning. Journal of Experimental Psychology: Applied, 18, 178-179. doi: $10.1037 / \mathrm{a} 0026923$

Just, M.A., \& Carpenter, P.A. (1992). A capacity theory of comprehension: Individual differences in working memory. Psychological Review, 99, 122-149. doi: 10.1037/0033-295X.99.1.122

Kammerer, Y., Meier, N., \& Stahl, E. (2016). Fostering secondary-school students' intertext model formation when reading a set of websites: The effectiveness of source prompts. Computers \& Education, 102, 52-64. doi: 10.1016/j.compedu.2016.07.001

Kingsley, T., \& Tancock, S. (2013). Internet inquiry: Fundamental competencies for online comprehension. The Reading Teacher, 67, 389-399. doi: 10.1002/TRTR.1223

Klinkenberg, J.E., \& Skaar, E. (2003). STAS: Standardisert test i avkoding og staving [STAS: Standarized test of decoding and spelling]. Hønefoss, Norway: Ringerike PPT.

Knoop-van Campen, C.A.N., Segers, E., \& Verhoeven, L. (2018). The modality and redundancy effects in multimedia learning in children with dyslexia. Dyslexia, 24, 140-155. doi: 10.1002/dys. 1585

Kurby, C.A., Britt, M.A., \& Magliano, J.P. (2005). The role of top-down and bottom-up processes in between-text integration. Reading Psychology, 26, 335-362. doi: 10.1080/02702710500285870

Leu, D.J., Kiili, C., \& Forzani, E. (2016). Infividual differences in the new literacies of online research and comprehension. In P. Afflerbach (Ed.), Handbook of individual differences in reading (pp. 259-272). New York: Routledge.

Lyon, G.R., Shaywitz, S.E., \& Shaywitz, B.A. (2003). A definition of dyslexia. Annals of Dyslexia, 53, 1-14. doi: 10.1007/s11881-003-0001-9

MacCullagh, L., Bosanquet, A., \& Badcock, N. (2017). University students with dyslexia: A qualitative exploratory study of learning practices, challenges, and strategies. Dyslexia, 23, 3-23. doi: 10.1002/dys. 1544

Mason, L., Junyent, A.A., \& Tornatora, M.C. (2014). Epistemic evaluation and comprehension of websource information on controversial science-related topics: Effects of a short-term instructional intervention. Computers \& Education, 76, 143-157. doi: 10.1016/j.compedu.2014.03.016

Mason, L., Pluchino, P., \& Tornatora, M.C. (2016). Using eye-tracking technology as an indirect instruction tool to improve text and picture processing and learning. British Journal of Educational Technology, 47, 1083-1095. doi: 10.1111/bjet.12271

Mason, L., Scheiter, K., \& Tornatora, M.C. (2017). Using eye-movements to model the sequence of textpicture processing for multimedia comprehension. Journal of Computer Assisted Learning, 33, 443460. doi: 10.1111/jcal.12191

Mayer, R.E. (2001). Multimedia learning. New York: Cambridge University Press.

Mayer, R.E. (2003). The promise of multimedia learning: Using the same instructional design methods across different media. Learning and Instruction, 13, 125-139. doi: 10.1016/S0959-4752(02)00016-6

Mayer, R.E. (2014a). Introduction to multimedia learning. In R.E. Mayer (Ed.), The Cambridge handbook of multimedia learning (pp. 1-24). New York: Cambridge University Press.

Mayer, R.E. (2014b). Cognitive theory of multimedia learning. In R.E. Mayer (Ed.), The Cambridge handbook of multimedia learning (pp. 43-71). Cambridge: Cambridge University Press.

Mayer, R.E. (Ed.) (2014c), The Cambridge handbook of multimedia learning. New York: Cambridge University Press.

Mayer, R.E., Heiser, H., \& Lonn, S. (2001). Cognitive constraints on multimedia learning: When presenting more material results in less understanding. Journal of Educational Psychology, 93, 187-198. doi: 10 1037i/0022-0663 93.1187

Mayer, R.E., \& Moreno, R. (2010). Techniques that reduce extraneous cognitive load and manage intrinsic cognitive load during multimedia learning. In J.L. Plass, R. Moreno, \& R. Brünken (Eds.), Cognitive load theory (131-152). New York: Cambridge University Press. 
McCarthy, J.E., \& Swierenga, S.J. (2010). What we know about dyslexia and Web accessibility: A research review. Universal Access in the Information Society, 9, 147-152. doi: 10.1007/s10209-009-0160-5

Melby-Lervåg, M., Lyster, S.A.H., \& Hulme, C. (2012). Phonologival skills and their role in learning to read: A meta-analytic review. Psychological Bulletin, 138, 322-352. doi: 10.1037/a0026744

Menghini, D., Finzi, A., Carlesimo, G. A., \& Vicari, S. (2011). Working memory impairment in children with developmental dyslexia: Is it just a phonological deficity? Developmental Neuropsychology, 36, 199-213. doi: 10.1080/87565641.2010.549868

Moreno, R., \& Mayer, R.E. (2000). Engaging students in active learning: The case for personalized multimedia messages. Journal of Educational Psychology, 92, 724-733. DOI: 10.1037//002206M.92.4.724

Moreno, R., \& Mayer, R.E. (2002). Verbal redundancy in multimedia learning: When reading helps listening. Journal of Educational Psychology, 94, 156-163. doi: 10.1037//0022-0663.94.1.156

Myers, J.L., \& O'Brien, E.J. (1998). Accessing the discourse during reading. Discourse Processes, 26, 131157. doi: $10.1080 / 01638539809545042$

Paivio, A. (1971). Imagery and verbal processes. New York: Oxford University Press.

Paivio, A. (1986). Mental representations: A dual-coding approach. New York: Oxford University Press.

Pociask, F.D., \& Morrison, G.R. (2008). Controlling split attention and redundancy in physical therapy instruction. Educational Technology Research and Development, 56, 379-399. doi: 10.1007/s11423007-9062-5

Prado, C., Dubois, M., \& Valdois, S. (2007). The eye movements of dyslexic children during reading and visual search: Impact of the visual attention span. Vision Research, 47, 2521-2530. doi: 10.1016/j.visres.2007.06.001

Ramus, F., Rosen, S., Dakin, S.C., Day, B.L., Castellote, J.M., White, S., \& Frith, U. (2003). Theories of developmental dyslexia: Insights from a multiple case study of dyslexic adults. Brain, 126, 841-865. doi: 10.1093/brain/awg076

Rau, A.K., Moll, K., Snowling, M.J., \& Landerl, K. (2015). Effects of orthographic consistency on eye movement behavior: German and English children and adults process the same words differently. Journal of Experimental Child Psychology, 130, 92-105. doi: 10.1016/j.jecp.2014.09.012

Rayner, K., Ardoin, S.P., \& Binder, K.S. (2013). Children's eye movements in reading: A commentary. School Psychology Review, 42, 223-233.

Rayner, K., Chace, K.H., Slattery, T.J., \& Ashby, J. (2006). Eye movements as reflections of comprehension processes in reading. Scientific Studies of Reading, 10, 241-255. doi: 10.1207/s1532799xssr1003_3

Rieber, L.P., Tzeng, S.-C., \& Tribble, K. (2004). Discovery learning, representation, and explanation within a computer-based simulation: Finding the right mix. Learning and Instruction, 14, 307-323. doi: 10.1016/j.learninstruc.2004.06.008

Roca, J., Tejero, P., \& Insa, B. (2018). Accident ahead? Difficulties of drivers with and without reading impairment recognizing words and pictograms in variable message signs. Applied Ergonomics, 67, 83-90. doi: 10.1016/j.apergo.2017.09.013

Roeschl-Heils, A., Schneider, W., \& van Kraayenoord, C.E. (2003). Reading, metacognition, and motivation: A follow-up study of German students in grades 7 and 8. European Journal of Psychology of Education, 18, 75-86. doi: 10.1007/BF03173605

Rouet, J.-F., \& Britt, M.A. (2014). Multimedia learning from multiple documents. In R.E. Mayer (Ed.), The Cambridge handbook of multimedia learning (2nd ed., pp. 813-841). New York: Cambridge University Press.

Rukavina, I., \& Daneman, M. (1996). Integration and its effect on acquiring knowledge about competing scientific theories from text. Journal of Educational Psychology, 88, 272-287. doi: 10.1037/00220663.88.2.272

Salmerón, L., Strøms $\varnothing$, H.I., Kammerer, Y., Stadtler, M., \& van den Broek, P. (2018). Comprehension processes in digital reading. In M. Barzillai, J. Thomson, S. Schroeder, \& P. van den Broek (Eds.), Learning to read in a digital world (pp. 91-120). Amsterdam: John Benjamins. 
Schneider, W. (2011). Memory development in childhood. In U. Goswami (Ed.), The Wiley-Blackwell handbook of childhood cognitive development (2nd ed., pp. 347-376). Malden, MA: WileyBlackwell.

Schneps, M.H., Thomson, J.M., Chen, C., Sonnert, G., \& Pomplum, M. (2013). E-readers are more effective than paper for some with dyslexia. PLoS ONE, 8, e75634. doi: 10.1371/journal.pone.0075634

Schotter, E.R., Tran, R., \& Rayner, K. (2014). Don't believe what you read (only once): Comprehension is supported by regressions during reading. Psychological Science, 25, 1218-1226. doi: $10.1177 / 0956797614531148$

Schüler, A., Scheiter, K., \& van Genuchten, E. (2011). The role of working memory in multimedia instruction: Is working memory working during learning from text and pictures? Educational Psychology Review, 23, 389-411. doi: 10.1007/s10648-011-9168-5

Shaywitz, S.E., \& Shaywitz, B.A. (2008). Paying attention to reading: The neurobiology of reading and dyslexia. Development and Psychopathology, 20, 1329-1349. doi: 10.1017/S0954579408000631

Smith-Spark, J.H., \& Fisk, J.E. (2007). Working memory functioning in developmental dyslexia. Memory, 15, 34-56. doi: 10.1080/09658210601043384

Stanovich, K.E. (1986). Matthew effects in reading: Some consequences of individual differences in the acuistion of literacy. Reading Research Quarterly, 21, 360-407. doi: 10.1598/RRQ.21.4.1

Swanson, H.L., \& Trahan, M.F. (1992). Learning disabled readers' comprehension of computer mediated text: The influence of working memory, metacognition, and attribution. Learning Disabilities Research and Practice, 7, 74-86.

Sweller, J., Ayres, P., \& Kalyuga, S. (2011). Cognitive load theory. New York: Springer.

Taylor, M., Duffy, S., \& Hughes, G. (2007). The use of animation in higher education teaching to support students with dyslexia. Education + Training, 49, 25-35. doi: 10.1108/00400910710729857

Torcasio, S., \& Sweller, J. (2010). The use of illustrations when learning to read: A cognitive load theory approach. Applied Cognitive Psychology, 24, 659-672. doi: 10.1002/acp.1577

Torgersen, J.K. (2001). The theory and practice of intervention: Comparing outcomes from prevention and remediation studies. In A. Fawcett \& R. Nicolson (Eds.), Dyslexia: Theory and good practice (pp. 185-201). London: Fulton.

Torgersen, J.K., Alexander, A.W., Wagner, R.K., Rashotte, C.A., Voeller, K., Conway, T., et al. (2001). Intensive remedial instruction with severe reading disabilities: Immediate and long-term outcomes from two instructional approaches. Journal of Learning Disabilities, 34, 33-58. doi: 10.1177/002221940103400104

Trakhman, L.M.S., Alexander, P.A., \& Berkowitz, L.E. (in press). Effects of processing time on comprehension and calibration in print and digital mediums. The Journal of Experimental Education. Advance online publication. doi: 10.1080/00220973.2017.1411877

Van de Vijver, F.J., \& Harsveld, M. (1994). The incomplete equivalence of the paper-and-pencil and computerized versions of the General Aptitude Test Battery. Journal of Applied Psychology, 79, 852-859. doi: 10.1037/0021-9010.79.6.852

Van Roy, B. \& Pretorius, E.J (2013). Is reading in an agglutinating language different from an analytic language? An analysis of isiZulu and English reading based on eye movements. Southern African Linguistics and Applied Language Studies, 31, 281-297. doi: 10.2989/16073614.2013.837603

Van Strien, J.L.H., Brand-Gruwel, S., \& Boshuizen, H.P.A. (2014). Dealing with conflicting information from multiple nonlinear texts: Effects of prior attitudes. Computers in Human Behavior, 32, 101111. doi: $10.1016 /$ j.chb.2013.11.021

Vinje, F.E. (1982). Journalistspråket [The journalist language]. Fredrikstad, Norway: Institute for Journalism.

Yin, R.K. (2009). Case study research: Design and methods (4th ed.). Thousand Oaks, CA: Sage. 